\title{
Effect of Visitor Number on the Behavior and Cortisol Metabolites Concentrations of Sambar Deer (Cervus unicolor) in Captivity
}

\author{
Gholib Gholib $^{1 *}$, Sri Panggabean ${ }^{2}$, Sri Wahyuni ${ }^{3}$, Fadli A Ghani ${ }^{3}$, Abdullah \\ Hamzah $^{4}$, and Erdiansyah Rahmi ${ }^{5}$
}

\author{
Laboratory of Physiology, Faculty of Veterinary Medicine, Universitas Syiah Kuala, Banda Aceh, Indonesia. \\ ${ }^{2}$ Study Program of Veterinary Education, Faculty of Veterinary Medicine, Universitas Syiah Kuala, Banda Aceh, \\ Indonesia. \\ ${ }^{3}$ Laboratory of Anatomy, Faculty of Veterinary Medicine, Universitas Syiah Kuala, Banda Aceh, Indonesia. \\ ${ }^{4}$ Laboratory of Clinic, Faculty of Veterinary Medicine, Universitas Syiah Kuala, Banda Aceh, Indonesia. \\ ${ }^{5}$ Laboratory of Histology, Faculty of Veterinary Medicine, Universitas Syiah Kuala, Banda Aceh, Indonesia. \\ *Corresponding author. E-mail: erdian.ersan@unsyiah.ac.id
}

\begin{abstract}
The effect of the visitor on animal behavior in captivity has been widely reported. However, whether this visitor-effect also influences stress for captive animals is still limited and absent for captive Sambar deer (Cervus unicolor). Therefore, the objective of this study was to examine the effect of visitor numbers on the behavior and cortisol metabolites concentrations in captive Sambar deer. This study used 8 Sambar deer living in the Taman Rusa Lamtanjong, Aceh Besar. In total, 640 hours of behavior data were collected using focal animal sampling during two-month observations. During behavioral observations, the number of visitors to the Sambar deer cage was recorded and 35 fecal samples were collected. Fecal samples were then extracted and measured the cortisol metabolite concentration using a specific antibody, 11ßhydroxy-etiocholanolone, through an enzyme-linked immunosorbent assay (ELISA) method. Data were analyzed using a paired sample t-test and Spearman Rank correlation. The concentrations of cortisol metabolites were significantly higher when the presence of human visitors $(301.06 \pm 37.21 \mathrm{ng} / \mathrm{g}$ feces) compared to the absence of human visitors $(202.15 \pm 88.07 \mathrm{ng} / \mathrm{g}$ feces $)$ in the cage $(\mathrm{p}<0.01)$. In addition, the number of visitors was significantly correlated with the increase of cortisol metabolites concentrations ( $r s=0.510, p<0.01$ ). Moreover, the presence of human visitors influences the animal behaviors particularly decrease the feeding activity ( $r s=-0.232, p<0.05)$, and increase the foraging $(\mathrm{rs}=0.263, \mathrm{p}<0.05)$ and grooming $(\mathrm{rs}=0.355, \mathrm{p}<0.01)$ activities. In conclusion, the number of visitors affected the increases of cortisol metabolites concentrations and influences some of the animal behaviors.
\end{abstract}

Keywords: Animal behavior, Cortisol metabolites, Number of visitors, Sambar deer.

\section{INTRODUCTION}

One of the native deer in Indonesia is the Sambar deer (Cervus unicolor) [1]. This species is a protected species based on the decision letter of Indonesia Government Regulation No. 7/1999 and Minister of Forestry No. $305 /$ Kpts-11/1991. This species has been categorized as low-risk species in 2006. However, nowadays this species has been categorized as vulnerable species since 2008 by the International Union for Conservation of Nature (IUCN) [2]. This is because the population of this species declines as the result of forest destruction, illegal poaching, and the limited reproductive capacity of Sambar deer.
Ex-situ conservation for this species has been carried out such as in zoos which it is received public visitation. A study on the effect of visitors has been reported that visitors can have negative, positive, or neutral effects on zoo animal behavior and welfare [3]. Previous studies have been reported that visitors can give negative effects on animal behavior and welfare in response to the higher number of visitors such as in kangaroos [4], sika deer [5], orangutan [6], and siamangs [7]. The negative effects of visitors on zoo animals are likely driven by fear because of the large size of visitor or visitor behavior such as loud noises, sudden movement, or standing too close to animals [8]. Thus, it can be caused stress which can be measured behaviorally and physiologically through cortisol 
measurement. In contrast, the higher number of visitors can give positive effects such as in chimpanzees [9], dogs [10], and penguins [11]. These differences can be due to species-specific and conditions of the enclosure.

Sambar deer is an animal that is easily stressed. Therefore, it is important to evaluate the effect of visitor numbers on behavior and cortisol concentrations. The objective of this study was to evaluate the effect of visitor numbers on behavior and cortisol concentration in the presence or absence of visitors in captive Sambar deer.

\section{MATERIALS AND METHODS}

\subsection{Animals and study site}

The present study used eight Sambar deer (three adult males, four adult females, and one juvenile male) living in the zoo of Taman Rusa Lamtanjong, Aceh Besar, Indonesia for two months. The number of visitors, behavior observations, and fecal sample collection were conducted during two months of observation. Number of visitors and behavior data were observed from morning until evening (08.00 a.m. to 5.00 p.m.).

\subsection{Observation of visitor number}

Observation of visitor numbers was carried out from morning (08.00 a.m.) until evening (05.00 p.m.). The numbers of visitors were calculated based on the visitors that visited the Sambar deer cage per day.

\subsection{Observation of behaviors}

Observation of behavior was carried out from morning (08.00 a.m.) until evening (05.00 p.m.). The method of daily behavior observation of Sambar deer was focal animal sampling [12]. Behavioral data were recorded using the instantaneous sampling method every one minute [13]. The behavioral data observed included feeding, foraging, drinking, locomotion, resting, aggression, grooming, and ruminating. In total, 640 hours of behavior data were recorded.

\subsection{Fecal Sample Collection}

Collection of fecal samples was performed in the morning (08.00 to 10.00 a.m.). In total 35 fecal samples were collected. Fresh fecal samples were collected after defecation. After that, fecal samples were homogenized and $\sim 30 \mathrm{~g}$ of homogenized fecal sample was then put into a fecal tube and stored in a cooler box. Subsequently, fecal samples were transported to the Physiology Laboratory, Faculty of Veterinary Medicine, Universitas Syiah Kuala, and stored at $-20^{\circ} \mathrm{C}$ in the freezer before extracted and measured for cortisol metabolites measurement.

\subsection{Fecal Extraction}

The procedure of fecal extraction was adopted from the method of Gholib et al. [14]. The first, samples were taken out from the freezer and then thawed at $50^{\circ} \mathrm{C}$ for 1 to 2 hours. Second, approximately 0.5-0.6 g sample was filled into a $15 \mathrm{ml}$ centrifuge tube containing $4.5 \mathrm{ml}$ of $80 \%$ methanol. After that, samples were extracted by using a multivortexer for 15 minutes at $1000 \mathrm{rpm}$. Fecal solution was then centrifuged for 10 minutes at $3000 \mathrm{rpm}$. Finally, fecal extract was taken and filled into a $1.5 \mathrm{ml}$ microtube and stored at $-20^{\circ} \mathrm{C}$ in the freezer before cortisol metabolites measurement.

\subsection{Cortisol Metabolites Measurement}

The concentrations of cortisol metabolite from the fecal extract of Sambar deer were measured by using a specific assay 11ß-hydroxy etiocholanolone. The procedure for measuring the cortisol metabolite concentration was adopted from Gholib et al. [14]. First, $50 \mu 1$ standards of $11 \beta$-hydroxy etiocholanolone were filled into the standard well of the microplate. After that, $50 \mu \mathrm{l}$ fecal extract, and $50 \mu \mathrm{l}$ quality control were filled into sample wells and quality control wells of a microplate, respectively. Afterward, 50 $\mu$ l enzyme conjugate and $50 \mu \mathrm{l}$ antibody of $11 \beta$-hydroxy etiocholanolone were added into standard, samples, and quality control wells. The microplate was then mixed and covered with a sealer. The microplate was then incubated for 12 to 16 hours at $4^{\mathrm{O}} \mathrm{C}$ in a refrigerator. After incubation, the sealer was removed and then washed with washing buffer four times and then blotted dry using a towel paper. Each well of the microplate was then added by $150 \mu \mathrm{l}$ of streptavidin-peroxidase (Sigma, Germany) and incubated at room temperature for 30 minutes in dark. After the second incubation, the microplate was washed four times using washing buffer. After washing, each well of the microplate was filled with $150 \mu 1$ substrate solution and then incubated for 30-45 minutes in dark. Each well of microplate was added $50 \mu$ l stop solution $\left(2 \mathrm{M} \mathrm{H}_{2} \mathrm{SO}_{4}\right)$ to stop the enzyme reaction. Finally, absorbance was measured using the microplate spectrophotometer (ELISA reader) at $450 \mathrm{~nm}$ and the cortisol metabolites concentration was calculated by using a Program of MPM 6.

\subsection{Data analysis}

Data were analyzed by using Student's t-test to compare the cortisol metabolite concentrations when there were the presence of visitors and the absence of visitors. The correlation between the visitor number and the behavior data was analyzed by using the Spearman Rank correlation test. Data analyses were performed by using SPSS 20 and statistical significance was set to $\alpha=0.05$. 


\section{RESULTS AND DISCUSSION}

\subsection{Effect of visitor numbers on the cortisol metabolite concentrations}

During the study observations, in total 707 visitors have been visited the Sambar deer's enclosure (Figure 1). The number of visitors varies each week. In the $2^{\text {nd }}$ to $5^{\text {th }}$ weeks of observation, the number of visitors was higher compared to the others week. This is because the $2^{\text {nd }}$ to $5^{\text {th }}$ week of observation is the school holidays. This result in line with a study that reported one of the factors of visitor attendance is a school holiday [15]. The sex of visitors is $51 \%$ male and $49 \%$ female which they visited the Sambar deer with a family group. The distance between visitors and the deer enclosure is less than one meter. Therefore, it may affect the stress of Sambar deer.

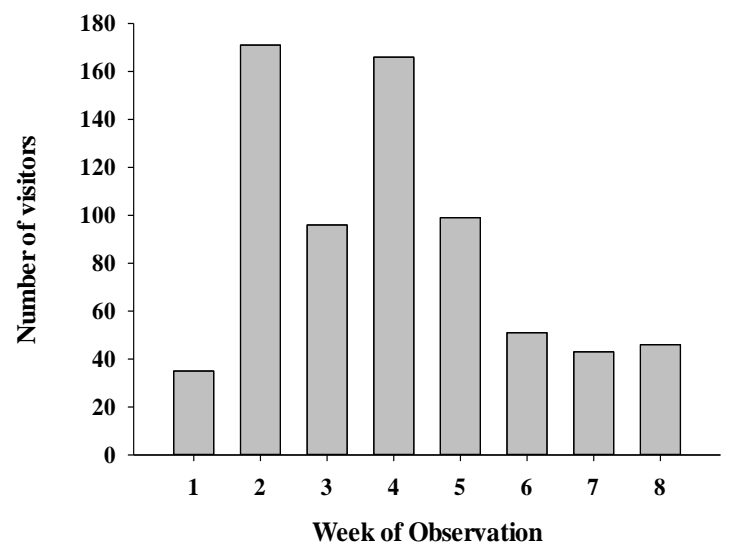

Figure 1. Number of visitors during the study period

Results of this study showed that concentrations of cortisol metabolites were significantly higher $(p<0.05)$ when the presence of human visitors $(295.24 \pm 35.67 \mathrm{ng} / \mathrm{g}$ dry feces) compared to the absence of human visitors $(202.15 \pm 17.61 \mathrm{ng} / \mathrm{g}$ feces) in the cage (Figure 2. Moreover, the number of visitors was also significantly correlated with the cortisol metabolites concentrations ( $\mathrm{rs}=0.510, \mathrm{p}$ $<0.01)$. A positive correlation between the visitor number and cortisol metabolite concentration indicates that increasing the number of visitors will increase the concentration of cortisol metabolite.

These results indicated that the presence of visitor influence the increase of cortisol metabolites. This evidence is likely driven by fear due to the visitor standing very close to the Sambar's enclosure and visitor activities (e.g., talking loudly, noisily, etc.). It suggests that visitors may be a stressor for Sambar deer because Sambar deers are stressed animals. This stressor will stimulate the hypothalamus to secrete corticotrophin-releasing-hormone (CRH), a neuropeptide hormone. The $\mathrm{CRH}$ then stimulates the anterior pituitary to produce an adrenocorticotrophic hormone (ACTH). ACTH stimulates the adrenal glands to produce cortisol [14].

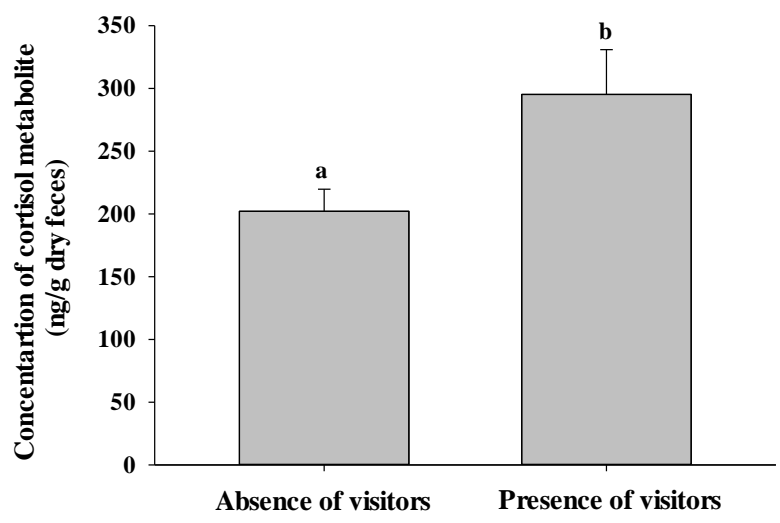

Figure 2. The concentration of cortisol metabolite (mean $\pm \mathrm{SD}$ ) when there were the presence of visitors and the absence of visitors. Different superscripts above the histogram showed a significantly different $(\mathrm{p}<0.05)$.

These results similar to previous studies in which visitor number was related to increased glucocorticoid (cortisol) in the urine of spider monkeys [16] and also in fecal of Mexican wolves [17], and blackbuck [18]. In contrast, this study differs from the study in black-capped capuchins that glucocorticoid decreased with the presence of visitors. These differences because black-capped capuchins seem habituated to visitor presence. Sherwen and Hemsworth [4] stated that visitors can have positive, negative, or neutral effects on zoo animals.

\subsection{Effect of visitor numbers on the daily behavior}

Results of this study showed that the visitor number affected the daily behavior of Sambar deer. The presence of human visitors influenced the animal behaviors particularly decreasing significantly the feeding activity $(\mathrm{rs}=-0.232, \mathrm{p}<0.05)$. Moreover, the presence of human visitors also significantly influenced the increase of foraging ( $\mathrm{rs}=0.263, \mathrm{p}<0.05)$ and grooming $(\mathrm{rs}=0.355$, $\mathrm{p}<0.01$ ) activities (Table 1).

Behavior changes of zoo animals have been reported from previous studies. The higher number of visitors has been associated with the lower frequencies of feeding in Mexican wolves [17]. In contrast, in Chimpanzees, the higher number of visitors influenced the decrease of foraging, grooming, and playing activities [19]. Another behavior change that has been associated with the higher number of visitors from previous studies is the increase of aggression rates such as in baboons [20], Indian gaur [21], and gorillas [22]. This result suggests that different animal will display different change of behavior which it is likely driven by fear. 
Table 1. Relationship between the number of visitor and Sambar deer's behavior

\begin{tabular}{|c|c|c|c|}
\hline Behavior & rs & $\begin{array}{l}\mathrm{p}- \\
\text { value }\end{array}$ & Notes \\
\hline Feeding & -0.232 & 0.039 & $\begin{array}{l}\text { negative cor, not } \\
\text { sig. }\end{array}$ \\
\hline Foraging & 0.263 & 0.018 & positive cor, sig. \\
\hline Drinking & -0.098 & 0.390 & $\begin{array}{l}\text { negative cor, not } \\
\text { sig }\end{array}$ \\
\hline Locomotion & 0.051 & 0.656 & $\begin{array}{l}\text { positive cor, not } \\
\text { sig. }\end{array}$ \\
\hline Resting & 0.149 & 0.186 & $\begin{array}{l}\text { positive cor, not } \\
\text { sig }\end{array}$ \\
\hline Aggression & 0.110 & 0.331 & $\begin{array}{l}\text { positive cor, not } \\
\text { sig }\end{array}$ \\
\hline Grooming & 0.355 & 0.001 & positive cor, sig \\
\hline Ruminating & -0.044 & 0.701 & $\begin{array}{l}\text { negative cor, not } \\
\text { sig }\end{array}$ \\
\hline \multicolumn{4}{|c|}{$\begin{array}{ll}\text { Note: } & \text { Negative cor }=\text { negative correlation } \\
& \text { Positive cor }=\text { positive correlation } \\
& \text { Not sig }=\text { not significant }(p>0.05) \\
& \text { Sig }=\text { significant }(\mathrm{p}<0.05)\end{array}$} \\
\hline
\end{tabular}

Have seen that visitors have a negative impact on zoo animals, this can be a concern for zoo managers. Because this can have an effect on risks to animal welfare and the visitor experiences [4]. If visitors are thought to be a trigger for fear for zoo animals, then long-term exposure can be a source of recurring acute or chronic stress. In addition, the changes in the behaviors of the animals, such as avoiding, hiding, aggression, less feeding, and playing, will have implications for unfavorable visitor experiences. Therefore, it is very important for zoo managers to fully understand this relationship so that the risk of negative impacts on visitors can be reduced or managed.

\section{CONCLUSION}

In conclusion, the number of visitors affected the increase of cortisol metabolites concentrations and influence some of the animal behaviors particularly decreasing the feeding activity and increasing the foraging and grooming activities.

\section{AUTHORS' CONTRIBUTIONS}

All authors equally contributed to the preparation and editing of the manuscript.

\section{ACKNOWLEDGMENTS}

We thank Universitas Syiah Kuala for funding this study through Research Grant Scheme: Penelitian Lektor (Lector Research). We also gratefully thank Taman Rusa Lamtanjong, Aceh Besar for the permission to conduct this study.

\section{REFERENCES}

[1] E. Susanty, Teknik konsentrasi formol eter untuk mendiagnosa parasit usus. Jurnal Kesehatan Melayu 1(2) (2018) 125-129.

[2] G. Semiadi, Y. Jamal, The nutritional quality of captive sambar deer (Rusa unicolor brookei Hose, 1893) velvet antler. Biodiversitas, 16(2) (2015) 156160

[3] International Union for Conservation of Nature (IUCN). IUCN Red List of Species, Sambar Deer (Cervus unicolor). 2015. http://www.iucnredlist.org [12 Oktober 2020].

[4] S.L. Sherwen, P.H. Hemsworth, The visitor effect on zoo animals: implications and opportunities for zoo animal welfare. Animals 9 (2019) 366.

[5] S.L. Sherwen, P.H. Hemsworth, K.L. Butler, K.V. Fanson, M.J. Magrath, Impacts of visitor number on Kangaroos housed in free-range exhibits. Zoo Biol. 34 (2015) 287-295.

[6] L. Shen-Jin, P.A. Todd, Y. Yan, Y. Lin, F. Hongmei, W. Wan-Hong, The effects of visitor density on sika deer (Cervus Nippon) behaviour in Zhu-Yu-Wan Park, China. Anim. Welf. 19 (2010) 61-65.

[7] L.E. Birke, Effects of browse, human visitors and noise on the behaviour of captive orang-utans. Anim. Welf. 11 (2002) 189-202.

[8] K.N. Smith, C.W. Kuhar, Siamangs (Hylobates syndactylus) and white-cheeked gibbons (Hylobates leucogenys) show few behavioral differences related to zoo attendance. J. Appl. Anim. Welf. Sci. 13 (2010) 154-163.

[9] J.A. Rushen, A. Taylor, A.M. De Passillé, Domestic animals fear of humans and its effect on their welfare. Appl. Anim. Behav. Sci. 65 (1999) 285-303.

[10] S. Cook, G.R. Hosey, Interaction sequences between chimpanzees and human visitors at the Zoo. Zoo Biol. 14 (1995) 431-440.

[11] A.E. Eltorai, R.W. Sussman, The visitor effect and captive black-tailed prairie dog behavior, Der Zool. Gart. 79 (2010) 109-120.

[12] C.K. Collins, T. Quirke, T., Overy, L., Flannery, K. and O'Riordan, R. 2016. The effect of the zoo setting on the behavioural diversity of captive gentoo penguins and the implications for their educational potential. J. Zoo Aquar. Res. 4: 85-90.

[13] J. Altmann, Observational study of behaviour: sampling methods. Behaviour 49 (1974) 227-267. 
[14] P. Martin, P. Bateson, Measuring Behaviour: an Introductory Guide, 2nd ed, Cambridge University Press, Cambridge, 1993.

[15] G. Gholib, F.H.R.A. Pampang, T.M. Lubis, M. Adam, M. Jalaluddin, R. Razali, A. Azhar, T.F. Karmil, Non-invasive measurement of cortisol metabolite in feces of toraya buffalo by using enzyme immunoassay technique. E3S Web of Conferences, (2020). 151:01061.https://doi.org/10.1051/e3sconf/20201 5101061.

[16] A.W. Whitworth, An investigation into the determining factors of zoo visitor attendance in UK zoos. PloS One 7(1) (2012) 1-10.

[17] N. Davis, C.M. Schaffner, T.E. Smith, Evidence that zoo visitors influence HPA activity in spider monkeys (Ateles geoffroyii rufiventris). Appl. Anim. Behav. Sci. 90 (2005) 131-141.

[18] M. Pifarre, R. Valdez, C. Gonzalez-Rebeles, C. Vazquez, M. Romano, F. Galindo, The effect of zoo visitors on the behavior and faecal cortisol of the Mexican wolf (Canis lupus baileyi). Appl. Anim. Behav Sci. 123 (2012) 57-62.

[19] T. Rajagopal, G. Archunan, M. Sekar, Impact of zoo visitors on the fecal cortisol levels and behavior of an endangered species: Indian blackbuck (Antelope cervicapra L.). J. Appl. Anim. Welf. Sci. 14 (2011) 18-32.

[20] W. Wood, Interaction among environmental enrichment, viewing crowds, and zoo chimpanzees (Pan troglodytes). Zoo Biol. 17 (1998) 211-230.

[21] T.S Bortolini, J.C. Bicca-Marques, The effect of environmental enrichment and visitors on the behavior and welfare of two captive hamadryas baboons (Papio hamadryas). Anim. Welf. 20 (2011) 573.

[22] M. Sekar, T. Rajagopal, G. Archunan, Influence of zoo visitor presence on the behaviour of captive Indian gaur (Bos gaurus gaurus) in a zoological park. J. Appl. Anim. Welf. Sci. 11 (2008) 352-357.

[23] C.W. Kuhar, Group differences in captive gorillas reaction to large crowds. Appl. Anim Behav. Sci. 110 (2008) 377-385 